\title{
Radiation-induced reduction of mixed silver and rhodium ionic aqueous solution
}

\author{
Kanjiro Torigoe ${ }^{\mathrm{a} *}$, Hynd Remita ${ }^{\mathrm{a}}$, Patricia Beaunier ${ }^{\mathrm{b}}$, Jacqueline Belloni $^{\mathrm{b}}$ \\ a Laboratoire de Chimie Physique, associé au CNRS, Université Paris-Sud, Bât. 350, 91405 Orsay Cedex, France \\ ${ }^{\mathrm{b}}$ Laboratoire de Réactivité de Surface, UMR 7609, CNRS-Paris VI, 4 Place Jussieu, 75252 Paris Cedex 05, France
}

Received 1 February 2001; accepted 8 June 2001

\begin{abstract}
Silver and rhodium metal nanoparticles were synthesized by electron beam and $\gamma$-radiolysis of mixed solutions containing $\left(\mathrm{Rh}^{\mathrm{II}}\right.$ acetate) dimer and $\mathrm{Ag}^{+}$sulfate in variable proportions. From the observation of the optical absorption spectra, transmission electron microscopic images and local X-ray analysis at increasing doses, it is concluded that the metals are segregated into two populations, which are randomly distributed according to the mixture content, one of 1.5-2 nm pure rhodium clusters, and the other of $15-20 \mathrm{~nm}$ pure silver clusters. At complete reduction of both metals, the Ag nanoparticles are systematically surrounded by the small rhodium clusters. (C) 2002 Elsevier Science Ltd. All rights reserved.
\end{abstract}

\section{Introduction}

Multimetallic nanocrystals attract interest in several fields in view of their thermodynamic, electromagnetic, optical and catalytic properties (Belloni, 1996; Belloni et al., 1998; Braunstein et al., 1999; Henglein, 1993; Mulvaney, 1996; Schmid, 1994). Among various preparation methods (Michaelis et al., 1994; Harada et al., 1994; Tong et al., 1996; Torigoe et al., 1993), the radiolytic synthesis of nanocrystals from metal ions in solution can provide a wide variety of mono- and multimetallic systems with different structures (Belloni, 1996; Belloni et al., 1998). For instance, we have recently shown that the structure of $\mathrm{Ag}-\mathrm{Au}$ composite particles depend on the dose rate of $\gamma$-irradiation (Tréguer et al., 1998): for lower dose rates, UV-visible absorption and electron diffraction investigations demonstrate that the mixed metal particles display bilayered core-shell $\mathrm{Au}-$ $\mathrm{Ag}$ structure, while for higher dose rates they are found to be alloyed. On the other hand, in Cu-Pd (Marignier et al., 1985) and Ag-Pd (Remita et al., 1997) systems, alloyed particles are formed even under very low dose

\footnotetext{
*Corresponding author. Present address: Department of Industrial Chemistry, Science University of Tokyo, 1-3 Kagurazaka, Shinjuku-ku, Tokyo 162-8601, Japan.
}

rate conditions, while in $\mathrm{Au}-\mathrm{Pt}$ systems, bilayered structure was preponderant even at the highest dose rate available (Remita et al., 1999). We have explained these results by a competitive mechanism between the reduction of both kinds of metal ions by hydrated electrons and the redox reaction by electron transfer from the less noble metal to the more noble metal (de Cointet et al., 1997, Tréguer et al., 1998).

The aim of the present work is to investigate these reactions in the case of the $\mathrm{Ag}-\mathrm{Rh}$ system, because it is known that alloying between silver and rhodium was never obtained by conventional chemical reduction of the ion mixture or by metallurgy (Hansen and Shunk, 1958). On the other hand, the radiolytic method, particularly in the regime of pulsed electron beam with a high dose rate, has proven its efficiency to create alloyed or bilayered clusters (Belloni, 1996; Belloni et al., 1998). Thus, we intend to observe whether alloying of rhodium and silver could be achieved, at least in clusters, by radiation-induced radiolysis of variable dose rates.

\section{Experimental}

We have selected the rhodium acetate complex, which does not contain any halide ion as ligand, in order to 
prevent precipitation during the radiolysis study of mixtures of rhodium and silver ions.

\subsection{Materials}

Silver sulfate $\left(\mathrm{Ag}_{2} \mathrm{SO}_{4}\right.$, Alfa), rhodium ${ }^{\mathrm{II}}$ acetate dimer $\left(\left[\mathrm{Rh}\left(\mathrm{OCOCH}_{3}\right)_{2}\right]_{2}\right.$, Alfa) and 2-propanol (Prolabo) of reagent grade were used as received. For stabilizing the metal nanoparticles, poly(vinyl alcohol) (PVA, 99\% hydrolyzed, $\mathrm{MW}=85000$, Aldrich) was used without further purification. Water was deionized with a Millipore Alpha-Q system.

\subsection{Procedure}

Aqueous solutions $\left(6 \mathrm{~cm}^{3}\right.$ each) containing $10^{-3}$ moll $1^{-1}$ of total metal ion concentration, $0.1 \mathrm{moll}^{-1}$ of PVA in monomers or $5 \times 10^{-5} \mathrm{moll}^{-1}$ in polymer chains (as the stabilizer), and $0.2 \mathrm{moll}^{-1}$ of 2-propanol (as the main $\mathrm{OH}$ radical scavenger, but alcohol groups of PVA are also efficient) were prepared in glass vessels with a rubber plastic septum. The vessels were deaerated by flushing nitrogen for $15 \mathrm{~min}$. Then they were irradiated by either $\gamma$-rays from a ${ }^{60} \mathrm{Co}$ source of $7000 \mathrm{Ci}$ (dose rate: $6.6 \mathrm{kGy} \mathrm{h}^{-1}$ ) at our laboratory or a beam of an electron accelerator $\left(7.9 \mathrm{MGy} \mathrm{h}^{-1}\right)$ at Laboratoire CARIC-IONISOS. UV-visible absorption spectra were recorded with a Varian DMS100S spectrophotometer. TEM observations were performed with a JEOL 100CXII transmission electron microscope at an accelerating voltage of $100 \mathrm{kV}$, equipped with the Oxford Instruments energy dispersive spectrometer AN 10000 for $\mathrm{X}$-ray analysis. The sample drops were deposited and dried on carbon-coated copper grids.

\section{Results and discussion}

\subsection{Rhodium solutions}

The radiolysis of solutions of the rhodium salt alone (without silver ions) was investigated initially, under the same conditions as the following study of the silverrhodium mixture. The evolution of the optical absorption spectrum at increasing $\gamma$-dose (dose rate of $\left.6.6 \mathrm{kGy} \mathrm{h}^{-1}\right)$ of a solution of $\left(\mathrm{Rh}^{\mathrm{II}} \text { acetate }\right)_{2}$ dimer at $2.5 \times 10^{-4} \mathrm{moll}^{-1}\left(5 \times 10^{-4} \mathrm{moll}^{-1}\right.$ in $\left.\mathrm{Rh}^{\mathrm{II}}\right)$ is given in Fig. 1. The initial spectrum of the dimer salt presents a maximum at $220 \mathrm{~nm}$ and a shoulder at $250 \mathrm{~nm}$. With the increasing dose, the absorbance increases in the $200-800 \mathrm{~nm}$ range up to a plateau at $4.5 \mathrm{kGy}$ which is considered as corresponding to the complete reduction of the ions into $\mathrm{Rh}^{0}$ clusters, (Fig. 1, inset). A small peak is still seen at $220 \mathrm{~nm}$ in addition to an absorbance monotonously increasing in intensity when the wavelength decreases to the UV. The absorbance beyond

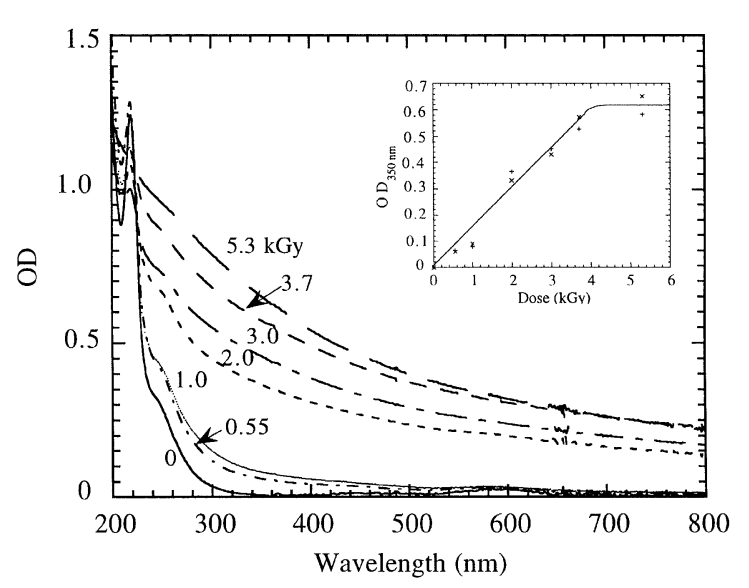

Fig. 1. Evolution with the dose of the optical absorption spectrum of a rhodium acetate dimer solution irradiated by $\gamma$ radiolysis. $5 \times 10^{-4} \mathrm{moll}^{-1}\left[\mathrm{Rh}^{\mathrm{II}}\left(\mathrm{OCOCH}_{3}\right)_{2}\right]_{2}, 0.2 \mathrm{moll}^{-1} 2$ propanol, $0.1 \mathrm{moll}^{-1}$ PVA. Dose rate: $6.6 \mathrm{kGy} \mathrm{h}^{-1}$. Optical path $0.2 \mathrm{~cm}$. Inset: Dose dependence of the absorbance at $350 \mathrm{~nm}$.

complete reduction of $\mathrm{Rh}^{\mathrm{II}}$ into $\mathrm{Rh}^{0}$ clusters at the plateau corresponds to extinction coefficients of the clusters, for instance at 220,350 and $520 \mathrm{~nm}$, of $\varepsilon_{220}=$ $1.2 \times 10^{4}, \varepsilon_{350}=6.2 \times 10^{3}$ and $\varepsilon_{520}=3 \times 10^{3} 1 \mathrm{~mol}^{-1} \mathrm{~cm}^{-1}$ per $\mathrm{Rh}$ atom, respectively. From the slope of the linear increase in Fig. 1, inset, the reduction yield of the bivalent rhodium ions into $\mathrm{Rh}$ atoms is derived as $G=0.27 \mu \mathrm{mol} \mathrm{J}^{-1}\left(G_{\text {red }}=0.54 \mu \mathrm{mol} \mathrm{J}^{-1}\right)$. Since the total reduction yield in aqueous isopropanol solutions is $G_{\text {red }}=0.60 \mu \mathrm{mol} \mathrm{J}^{-1}$, almost all the solvated electrons and hydroxyalkyl radicals formed by radiolysis of 2propanol solutions are indeed scavenged by $\mathrm{Rh}^{\mathrm{II}}$ ions of the dimeric rhodium acetate eventually to yield rhodium clusters.

In contrast to certain other metal ions such as $\mathrm{Au}^{\mathrm{III}}$ (Gachard et al., 1998), Ir ${ }^{\mathrm{III}}$ (Mills and Henglein, 1985), $\mathrm{Pt}^{\mathrm{II}}$ (Keghouche, 1983), $\mathrm{Pd}^{\mathrm{II}}$ (Michaelis and Henglein, 1992), etc for which the monovalent ions are stable, at least at low doses (Gachard et al., 1998), no induction time (Fig. 1, inset) is observed in the increase of the $\mathrm{Rh}_{n}$ absorbance with the $\gamma$-irradiation dose. Rhodium ions are thus progressively replaced by rhodium atoms, then included in clusters.

The rhodium clusters are observed by transmission electron microscopy. The micrographs of samples with incomplete reduction show that the rhodium clusters are randomly separated on the grid and that their size is in the average of $1-2 \mathrm{~nm}$ (Fig. 2a, $0.6 \mathrm{kGy}$ ). Considering this size of $\mathrm{Rh}$ clusters, their nuclearity is around $10^{3}$ atoms and their concentration is $10^{-6} \mathrm{moll}^{-1}$, that corresponds in average to 500 polymer chains per cluster. 

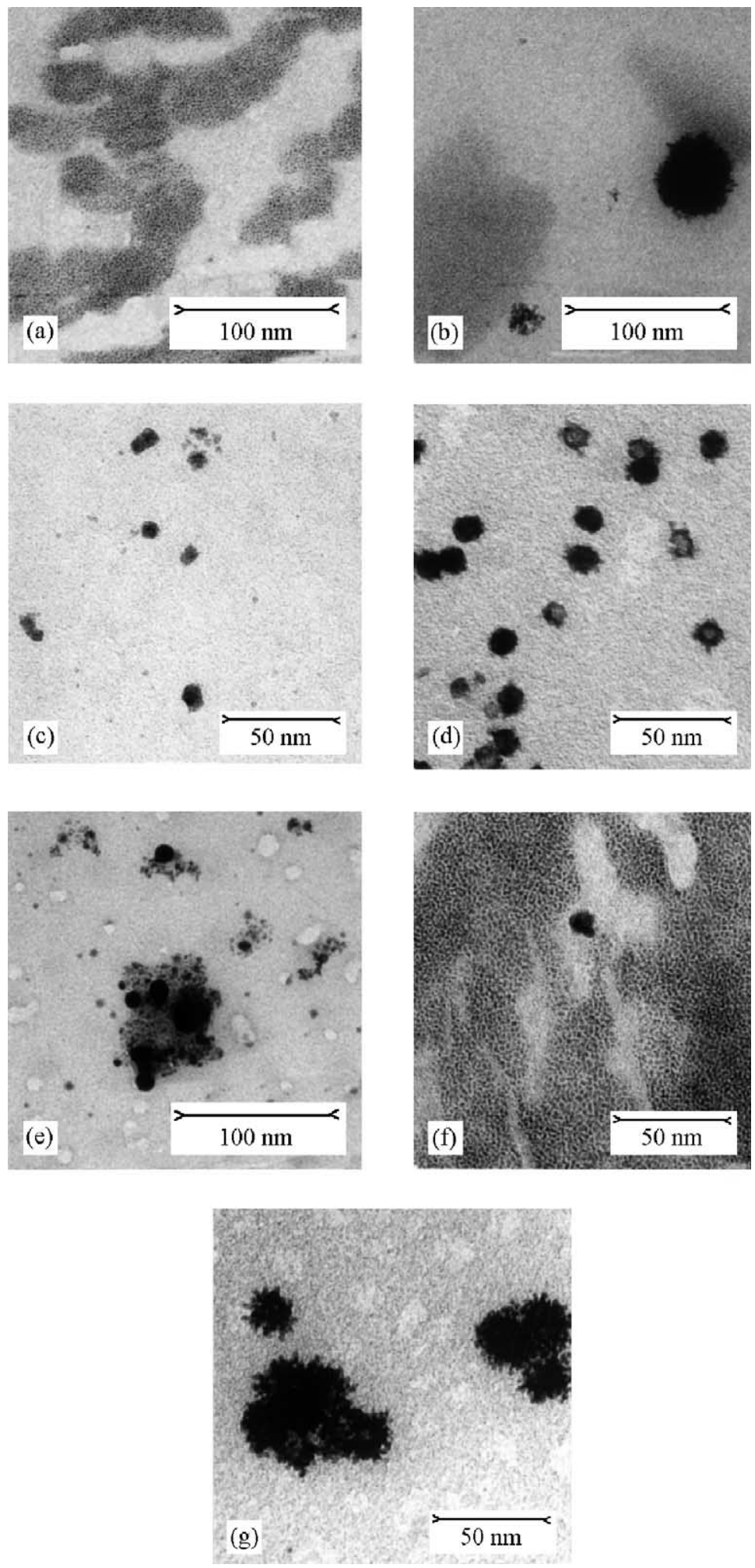

Fig. 2. Images by transmission electron microscopy of samples prepared by $\gamma$-radiolysis (Dose rate: $6.6 \mathrm{kGy} \mathrm{h}^{-1}$ ) or irradiation by electron beam (Dose rate: $7.9 \mathrm{MGy} \mathrm{h}^{-1}$ ). Total ion concentration $10^{-3} \mathrm{moll}^{-1} \cdot 0.2 \mathrm{moll}^{-1}$ 2-propanol, $0.1 \mathrm{moll}^{-1} \mathrm{PVA}$ (a) $\mathrm{Rh}^{\mathrm{II}}$ alone $\gamma$-dose $0.6 \mathrm{kGy}$. (b) $\mathrm{Rh}^{\mathrm{II}}$ alone. $\gamma$-dose $4 \mathrm{kGy}$. (c) $\left[\mathrm{Ag}^{\mathrm{I}}\right] /\left[\mathrm{Rh}^{\mathrm{II}}\right]=1 / 1 . \gamma$-dose $0.7 \mathrm{kGy}$. (d) $\left[\mathrm{Ag}^{\mathrm{I}}\right] /\left[\mathrm{Rh}^{\mathrm{II}}\right]=1 / 1 . \gamma$-dose $2.5 \mathrm{kGy}$. (e) $\left[\mathrm{Ag}^{\mathrm{I}}\right] /$ $\left[\mathrm{Rh}^{\mathrm{II}}\right]=1 / 1$. Electron beam, $2.5 \mathrm{kGy}$. (f) $\left[\mathrm{Ag}^{\mathrm{I}}\right] /\left[\mathrm{Rh}^{\mathrm{II}}\right]=1 / 3 . \gamma$-dose $0.7 \mathrm{kGy}$. (g) $\left[\mathrm{Ag}^{\mathrm{I}}\right] /\left[\mathrm{Rh}^{\mathrm{II}}\right]=1 / 3 . \gamma$-dose $4 \mathrm{kGy}$. 
However, beyond complete reduction (4kGy), aggregation into flocs of tens-hundreds of small clusters of the same size of $1-2 \mathrm{~nm}$ occurs as shown in Fig. 2b. This type of pattern was already observed for other metal clusters. The same flocs are found again if the sample is diluted three times before being evaporated on the grid, which suggests that the flocs pre-exist in the solution and do not result from the deposition on the grid. Another reaction is thus responsible for the floc formation. Before irradiation, the residual non-hydrolyzed carboxylic groups of the PVA polymer are in strong interaction with the ions and the polymer chain is developed in the solution. When all the ions are reduced at the cluster surface, the electrostatic repulsion between the clusters decreases. However, the PVA chains persist through multiple interactions with the metal surface to protect the clusters from coalescence. On the other hand, a few PVA radicals formed by the attack of alcohol groups by a part of primary OH. radicals (Ulanski et al., 1994, 1998; Wang et al., 1997) are no more scavenged by the metal ions. Thus, they react with polymer chains and initiate a few intra- or inter-molecular crosslinking between the chains. The process has been studied in neat PVA solutions and at very high dose even leads to the formation of nanogels (Ulanski et al., 1994, 1998; Wang et al., 1997) or films (Belloni et al., 1998). Therefore, an irradiation dose in excess towards complete ion reduction initiates some crosslinking events and the network of these few crosslinked polymer chains concentrates more closely some clusters into flocs.

\subsection{Bimetal rhodium-silver solutions}

\subsubsection{Equimolar solutions}

The ionic solutions to be irradiated contain a mixture of $\left(\mathrm{Rh}^{\mathrm{II}} \text { acetate }\right)_{2}$ dimer and $\mathrm{Ag}_{2} \mathrm{SO}_{4}$ salts with the same ion concentration of $5 \times 10^{-4} \mathrm{moll}^{-1}\left(\left[\mathrm{Ag}^{\mathrm{I}}\right] /\left[\mathrm{Rh}^{\mathrm{II}}\right]=1 / 1\right)$. The evolution of the absorption spectrum at increasing dose of $\gamma$-irradiation is somewhat different from that of pure rhodium solutions, as shown in Fig. 3. At $0.4 \mathrm{kGy}$, already, the specific plasmon band at $400 \mathrm{~nm}$ of silver clusters is present and the specific $220 \mathrm{~nm}$ peak of $\mathrm{Rh}^{\mathrm{II}}$ has also decreased, which indicates that both metals are partly reduced. At $310 \mathrm{~nm}$, which is a minimum in the surface plasmon spectrum of silver clusters, the absorbance increases slowly with the dose than in pure rhodium solutions up to $0.8 \mathrm{kGy}$, due to the competition for radical scavenging by silver ions. (Note that the rhodium acetate dimer is half less concentrated than the silver salt).

Then the absorbance increases at all the wavelengths but relatively less at around $400 \mathrm{~nm}$. The spectrum at the plateau contains a small peak close to $220 \mathrm{~nm}$ as in pure rhodium sols and a broad band centered at $400 \mathrm{~nm}$ as in pure silver sols.

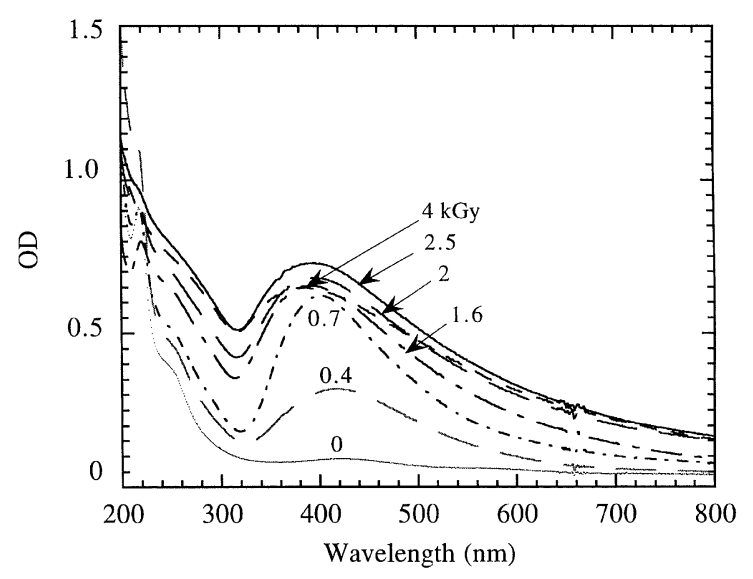

Fig. 3. Evolution with the dose of the optical absorption spectrum of a mixed solution $\mathrm{Ag} / \mathrm{Rh}^{\mathrm{II}}=1 / 1$ reduced by $\gamma$ radiolysis. $5 \times 10^{-4} \mathrm{moll}^{-1} \mathrm{Ag}^{\mathrm{I}}$, and $2.5 \times 10^{-4} \mathrm{moll}^{-1}\left[\mathrm{Rh}^{\mathrm{II}}(\mathrm{O}\right.$ $\left.\left.\mathrm{COCH}_{3}\right)_{2}\right]_{2}$ (or $5 \times 10^{-4} \mathrm{moll}^{-1} \mathrm{Rh}^{\text {II }}$ ions), $0.2 \mathrm{moll}^{-1} 2$ propanol, $0.1 \mathrm{moll}^{-1}$ PVA. Dose rate: $6.6 \mathrm{kGy} \mathrm{h}^{-1}$. Optical path $0.2 \mathrm{~cm}$.

Electron microscopy images (Fig. 2c) show two kinds of cluster populations at any dose. On the one hand, less abundant clusters are about $15-20 \mathrm{~nm}$ large. By local Xray analysis or by electron diffraction, they are found to contain exclusively silver atoms. On the other hand, more numerous clusters have a smaller size of $1.5-2 \mathrm{~nm}$ and they are made of pure rhodium as shown by X-ray analysis of groups of a few particles. They are too small for electron diffraction observation. They are present from the dose $0.7 \mathrm{kGy}$. A remarkable feature beyond complete reduction $(4.5 \mathrm{kGy})$ (Fig. $2 \mathrm{~d}$ ) is that all the large silver particles are surrounded by more numerous small rhodium clusters while at a lower dose the clusters were randomly distributed (Fig. 2c).

It appears from the spectrum evolution with the absorbed dose that silver ions are more easily reduced at low dose according to the ionic concentration which is double than that of the dimeric rhodium species $\left(\mathrm{Rh}^{\mathrm{II}}\right.$, $\left.\mathrm{Rh}^{\mathrm{II}}\right)$. The reduction mechanism of silver solutions (Buxton et al., 1988; Henglein and Tausch-Treml, 1981; von Pukies et al., 1968) has been more extensively studied than that of rhodium (Chibber et al., 1985; Derai et al., 1991). The rate constant of the reaction of $e_{\mathrm{aq}}^{-}$with $\mathrm{Ag}^{\mathrm{I}}$ is $k=3 \times 10^{10} 1 \mathrm{~mol}^{-1} \mathrm{~s}^{-1}$ (von Pukies et al., 1968), that is higher than that with $\mathrm{Rh}^{\mathrm{II}}$ ion dimers $k=(1-1.8) \times 10^{10} 1 \mathrm{~mol}^{-1} \mathrm{~s}^{-1}$ (Chibber et al., 1985; Derai et al., 1991). Moreover, monovalent silver ions are directly reduced into the zerovalent state, while two steps are required for bivalent rhodium ions. However, both metals are formed in the irradiated mixture at low doses.

Particularly significant is the observation, as here, of a separated nucleation of both types of metals (Figs. 2c 
and d). Coalescence of atoms/clusters of different metals is not observed. More usually in other mixed systems (Belloni et al., 1998; de Cointet et al., 1997; Marignier et al., 1985; Remita et al., 1997, 1999; Tréguer et al., 1998), the ions which are not yet reduced adsorb on the surface of the newly formed clusters, however they are made, of the same metal or of the other metal or of an alloy (Tréguer et al., 1998). The ions are then reduced in situ by the radiolytic radicals. The result of this successive adsorption and reduction process is the formation of bimetallic clusters. If the reduction process is followed by an intermetal electron transfer from the atoms of the less noble metal to the ions of the more noble metal, the resulting clusters are bilayered with a core of the more easily reduced metal, and a shell made of the other one. Otherwise, alloyed clusters are produced (Belloni et al., 1998; de Cointet et al., 1997; Marignier et al., 1985; Remita et al., 1997, 1999; Tréguer et al., 1998).

In contrast to the situation observed here, a segregation of silver and rhodium in separated clusters is unique. The segregation of metals $\mathrm{Rh}$ and $\mathrm{Ag}$ is also the rule in the chemical reduction of the mixture of the corresponding ions. Alloying of the metals is also not obtained in metallurgy (Hansen and Shunk, 1958). One reason that is invoked is the mismatch between the crystalline lattice $a_{0}$ parameters of $\mathrm{Rh}$ and $\mathrm{Ag}(0.3803$ and $0.4086 \mathrm{~nm}$, respectively). The fact that pure metal clusters of either silver or rhodium are found at least from $0.7 \mathrm{kGy}$ which means that there is no specific electron transfer from $\mathrm{Ag}^{0}$ or $\mathrm{Ag}_{n}$ to $\mathrm{Rh}^{\mathrm{II}}$ or reciprocally from $\mathrm{Rh}^{\mathrm{I}}, \mathrm{Rh}^{0}$ or $\mathrm{Rh}_{n}$ to $\mathrm{Ag}^{\mathrm{I}}$. It also means that rhodium ions, or more exactly the rhodium acetate dimers ( $\mathrm{Rh}^{\mathrm{II}}$ acetate $)_{2}$ do not adsorb easily on silver clusters and silver ions do not absorb on rhodium clusters. It seems here that the mismatch of crystal parameters between $\mathrm{Rh}$ and $\mathrm{Ag}$ prevents not only the coalescence between atoms and clusters of these two metals, but also the crossed adsorption of one type of ions on a cluster of the other metal. The ions are thus exclusively adsorbed on clusters of the same metal where they are reduced in situ to the zerovalent state by radicals. The result is that rhodium or silver atoms eventually cluster in pure isolated nuclei.

The final size of silver clusters is the same as in pure silver solutions under same conditions, but much larger than that of rhodium clusters. It seems that this difference pertains to the nature of the metal itself and is assigned (Belloni et al., 1998) to stronger interactions of the polymer with rhodium than with silver.

The particular micrograph pattern, found beyond complete reduction, of flocs containing silver clusters surrounded by small clusters of pure rhodium is also remarkable (Fig. 2d). When sols of pure silver or of pure rhodium clusters are prepared separately by $\gamma$-irradiation, then mixed, and samples are observed by electron microscopy, we observe that under the same final concentration conditions as above at complete reduction, the sizes are also $2 \mathrm{~nm}$ for rhodium and 15-20 nm for silver. However, the distribution of the various clusters on the grid is homogeneous as if this distribution had retained the memory of their independent synthesis in distinct solutions. We conclude therefore that, beyond complete reduction of the ion mixture, the formation of flocs containing both types of metal clusters is due to the reduction of both types of ions into separate clusters, and then, as for pure rhodium solutions irradiated with large doses (Fig. 2b), a partial crosslinking of the polymer chains which ensures consequently light interactions between rhodium and silver clusters. The optical absorption spectrum of irradiated mixed ion solutions at complete reduction is also different from that of the mixture after separate reduction by $\gamma$-irradiation of silver and rhodium solutions (Fig. 4). In the last case, the spectrum (Fig. 4a) corresponds to the convolution of the separated spectra of pure metal sols. In the case of the reduction of a mixed ion solution (Fig. 4b), the silver plasmon band maximum is shifted to the UV and the silver band is somewhat changed, in particular it is less intense and broader, as if rhodium had a strong influence on the silver absorption. Thus, the clusters are not just concentrated by the same polymer network in a floc with the small $\mathrm{Rh}$ clusters around one large silver cluster. It seems that some rhodium clusters are sufficiently close to the surface of the silver cluster which slightly modifies its surface plasmon absorption band as it is known from Mie theory for clusters coated by a thin layer of a second metal.

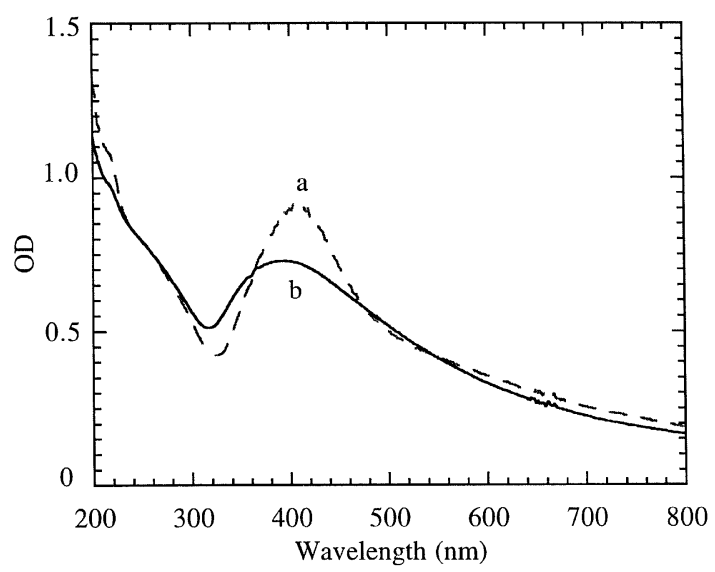

Fig. 4. Comparison between the optical absorption spectra of a mixture of pure $\mathrm{Rh}^{\mathrm{II}}$ and $\mathrm{Ag}^{\mathrm{I}}$ solutions $\gamma$-irradiated separately (a) and of an irradiated $\mathrm{Ag}^{\mathrm{I}} / \mathrm{Rh}^{\mathrm{II}}$ mixed solution (b), both at the same final concentrations and at a complete reduction (dose $4 \mathrm{kGy}$ ). Other conditions as in Fig. 3. 
It has been demonstrated (Tréguer et al., 1998) that, to favor alloying of two metals in the same cluster, their mixed ions should be reduced suddenly at a high rate before any electron transfer could occur from the atoms of the less noble metal to the ions of the more noble one. Therefore, equimolar solutions of silver-rhodium ions have also been irradiated up to a complete reduction at a very high dose rate by using the beam of an electron accelerator $\left(7.9 \mathrm{MGyh}^{-1}\right)$. The shape of the optical absorption spectrum at the end of the reduction is quite similar to the spectrum at full reduction by $\gamma$-radiolysis (Fig. $4 \mathrm{~b}$ ), with a maximum at $380 \mathrm{~nm}$, a very slight shoulder at $260 \mathrm{~nm}$ and a weak peak at $210 \mathrm{~nm}$ superimposed on the increasing absorbance to the UV. Local X-ray analysis shows that the clusters are almost pure either in rhodium or in silver. The cluster sizes measured by electron microscopy are slightly smaller than in $\gamma$-radiolysis: $1 \mathrm{~nm}$ for rhodium and $15 \mathrm{~nm}$ for silver. The silver clusters are systematically surrounded by the small rhodium clusters (Fig. 2e). In contrast to other mixed metal systems such as $\mathrm{Au}-\mathrm{Ag}$ (Tréguer et al., 1998), the alloying is not found even at the very high reduction rate (high dose rate). Moreover, the segregation between silver and rhodium is not only in a core-shell structure but is achieved in separated clusters as in $\gamma$ radiolysis results. We conclude again that due to a mismatch in crystal parameters the coalescence between zerovalent silver and rhodium and even the adsorption of one type of ions on the cluster of the other metal do not occur. Since these reactions do not interfere with the reduction rate, the overall process does not depend, in fact, on the dose rate.

Smaller sizes are found for rhodium and silver at a higher dose rate because ions are more quickly reduced into independent zerovalent nuclei and also because the influence of adsorption of ions on the clusters of the same metal is less important (Tréguer et al., 1998). A rough estimation based on the respective diameters and lattice parameters of both metal clusters indicates a relative abundance of a few hundreds of small rhodium clusters per large silver cluster in accordance with the electron microscopic images.

\subsubsection{Bimetallic solutions of rhodium-silver in various ion proportions}

Due to the lower value of $\mathrm{k}_{\mathrm{e}+\mathrm{Rh}}$ II relative to $k_{\mathrm{e}+\mathrm{Ag}}$ and the bivalent character of $\mathrm{Rh}^{\mathrm{II}}$, the fraction of radiolytic radicals scavenged by $\mathrm{Rh}^{\mathrm{II}}$ and $\mathrm{Rh}^{\mathrm{I}}$ is lower, relative to that by $\mathrm{Ag}^{\mathrm{I}}$ in equimolar solutions. However, it can be increased in solutions that are more concentrated in $\mathrm{Rh}^{\mathrm{II}}$ than in $\mathrm{Ag}^{\mathrm{I}}$.

The evolution with dose of the optical absorption spectrum of a solution $\mathrm{Ag} / \mathrm{Rh}^{\mathrm{II}}=1 / 3$ containing $2.5 \times 10^{-4} \mathrm{moll}^{-1} \mathrm{Ag}^{\mathrm{I}}$, and $3.75 \times 10^{-4} \mathrm{moll}^{-1}\left[\mathrm{Rh}^{\mathrm{II}}(\mathrm{O}-\right.$ $\left.\left.\mathrm{COCH}_{3}\right)_{2}\right]_{2}$ (or $7.5 \times 10^{-4} \mathrm{moll}^{-1} \mathrm{Rh}^{\mathrm{II}}$ ions), $0.2 \mathrm{moll}^{-1}$ 2-propanol, $0.1 \mathrm{moll}^{-1}$ PVA is shown in Figs. 5a (for the UV part) and $5 b$ (for the visible part). At $220 \mathrm{~nm}$ (Fig. 5a), the $\mathrm{Rh}^{\mathrm{II}}$ peak decays at increasing dose and a weak shoulder increases around $260 \mathrm{~nm}$. Above $2 \mathrm{kGy}$, the spectrum does not change anymore. An isosbestic point exists at $227 \mathrm{~nm}$. This means that at this wavelength the mean extinction coefficient of the mixed ion solution $\left(\mathrm{Ag} / \mathrm{Rh}^{\mathrm{II}}=1 / 3\right)$, which is essentially due to $\mathrm{Rh}^{\mathrm{II}}$, is just compensated by that of the mixed solution of $\mathrm{Ag}_{n}$ and $\mathrm{Rh}_{n}$ clusters. This also implies that both ions are reduced with the same proportion in this dose range.

At $400 \mathrm{~nm}$ (Fig. 5b), an intense band corresponding to the silver plasmon band increases first up to $1 \mathrm{kGy}$ and the intensity is half of that in $5 \times 10^{-4} \mathrm{moll}^{-1}$ solution. Then, at $2.5 \mathrm{kGy}$ when the reduction is achieved, a
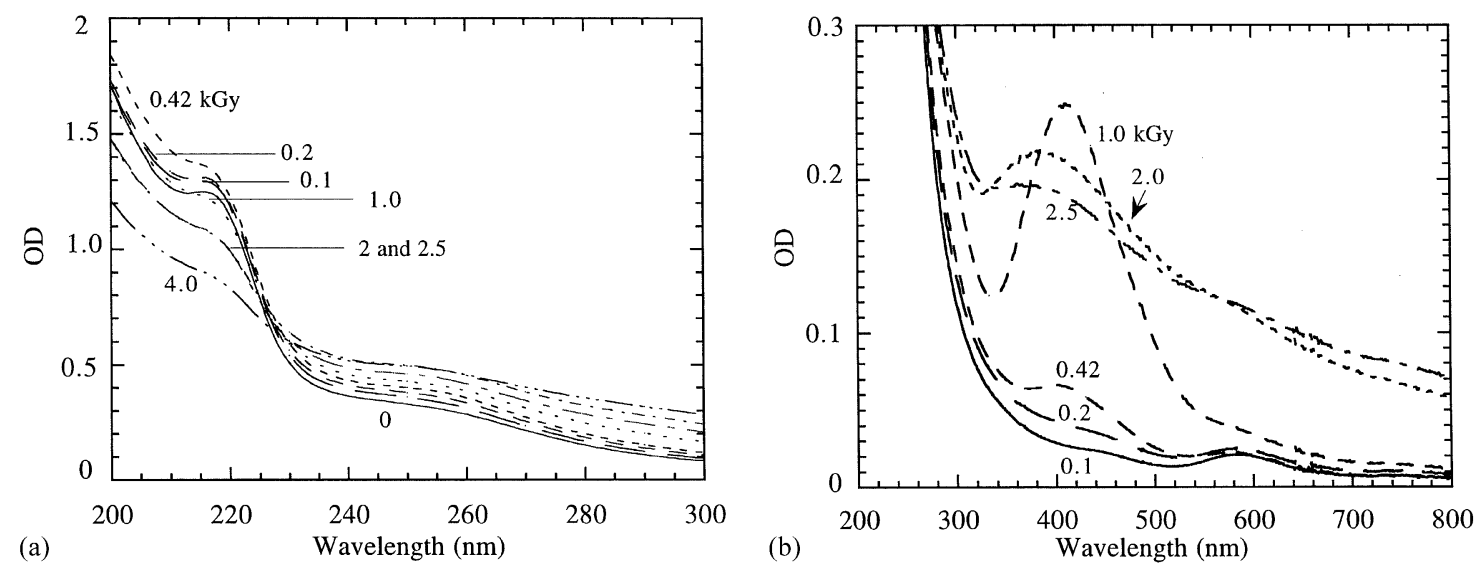

Fig. 5. Evolution with the dose of the optical absorption spectrum of a mixed solution $\operatorname{Ag}^{\mathrm{I}} / \mathrm{Rh}^{\mathrm{II}}=1 / 3$ reduced by $\gamma$-radiolysis. $2.5 \times 10^{-4} \mathrm{moll}^{-1} \mathrm{Ag}^{\mathrm{I}}$, and $3.75 \times 10^{-4} \mathrm{moll}^{-1}\left[\mathrm{Rh}^{\mathrm{II}}\left(\mathrm{OCOCH}_{3}\right)_{2}\right]_{2}\left(\right.$ or $7.5 \times 10^{-4} \mathrm{moll}^{-1} \mathrm{Rh}^{\mathrm{II}}$ ions), other conditions as in Fig. 3. (a) UV part. (b) Visible part. 


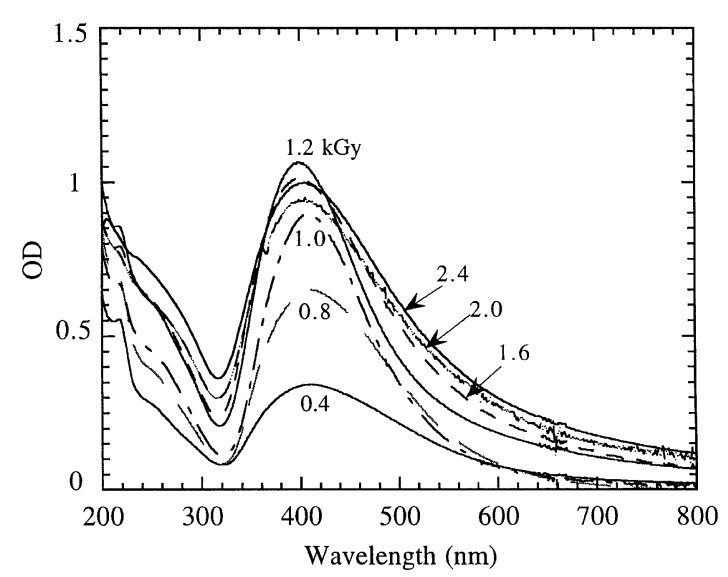

Fig. 6. Evolution with the dose of the optical absorption spectrum of a mixed solution $\mathrm{Ag}^{\mathrm{I}} / \mathrm{Rh}^{\mathrm{II}}=3 / 1$ reduced by $\gamma$ radiolysis. $7.5 \times 10^{-4} \mathrm{moll}^{-1} \mathrm{Ag}^{\mathrm{I}}$, and $1.25 \times 10^{-4} \mathrm{moll}^{-1}$ $\left[\mathrm{Rh}^{\mathrm{II}}\left(\mathrm{OCOCH}_{3}\right)_{2}\right]_{2}$ (or $2.5 \times 10^{-4} \mathrm{moll}^{-1} \mathrm{Rh}^{\mathrm{II}}$ ions), other conditions as in Fig. 3.

general absorbance increase at all the wavelengths corresponding to the $\mathrm{Rh}_{n}$ formation is superimposed. However, the spectrum is not an addition of the absorbance bands of both metals. Indeed, images by TEM present the same features as in the equimolar solutions. At partial reduction (Fig. 2f), two distinct populations of isolated large silver and small rhodium clusters coexist, and at complete reduction, pure silver clusters are surrounded by the small pure rhodium clusters (Fig. 2g), which explains as above that the silver band is partly masked by that of rhodium. Similar observations have been made for mixtures containing $\mathrm{Ag}^{\mathrm{I}} / \mathrm{Rh}^{\mathrm{II}}=1 / 9$.

For mixed solutions more rich in silver ions, such as a mixture $\mathrm{Ag}^{\mathrm{I}} / \mathrm{Rh}^{\mathrm{II}}=3 / 1 \quad$ containing $\quad 7.5 \times 10^{-4}$ $\mathrm{moll}^{-1} \mathrm{Ag}^{\mathrm{I}}$, and $1.25 \times 10^{-4} \mathrm{moll}^{-1}\left[\mathrm{Rh}^{\mathrm{II}}\left(\mathrm{OCOCH}_{3}\right)_{2}\right]_{2}$ (or $2.510^{-4} \mathrm{moll}^{-1} \mathrm{Rh}^{\mathrm{II}}$ ions), the surface plasmon band of silver clusters at $400 \mathrm{~nm}$ is an intense component of the spectrum with a deep minimum at $310 \mathrm{~nm}$ while the rhodium cluster component between 200 and $300 \mathrm{~nm}$ is weak at any dose (Fig. 6). The same observations were obtained for $\mathrm{Ag}^{\mathrm{I}} / \mathrm{Rh}^{\mathrm{II}}=9 / 1$ and $19 / 1$.

It is clear from the comparison between the spectra in Figs. 1, 3, 5 and $6\left(\mathrm{Ag}^{\mathrm{I}} / \mathrm{Rh}^{\mathrm{II}}=0 / 1,1 / 1,3 / 1,1 / 3\right.$, respectively) that the intensity of the absorbances at 220, 310 and $400 \mathrm{~nm}$ changes with the composition of the mixture at a constant total ion concentration and complete reduction. This variation is shown in Fig. 7. The absorbances for pure rhodium and silver clusters are plotted at the $\mathrm{Ag} /(\mathrm{Rh}+\mathrm{Ag})$ ratio values $0 \%$ and $100 \%$, respectively. The intensity decreases slightly and monotonously at $220 \mathrm{~nm}$ with the increasing silver content, according to the respective extinction coefficients. However, a striking feature is observed

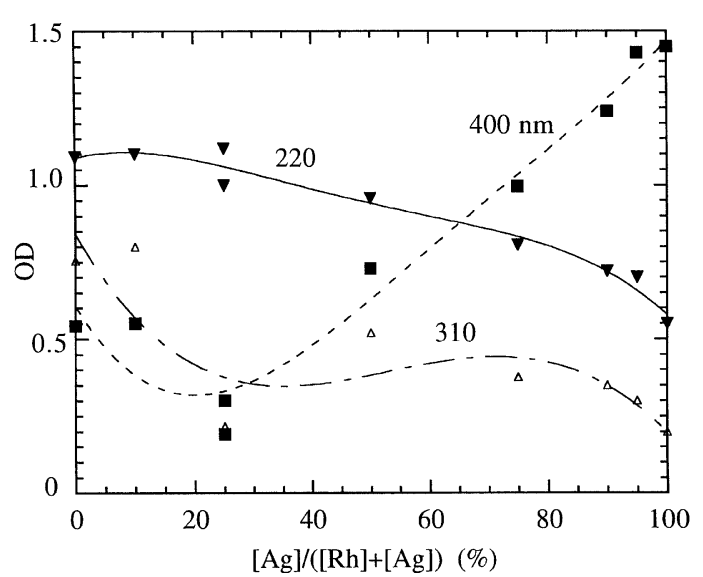

Fig. 7. Variation with the mixture composition, at a constant total metal concentration $10^{-3} \mathrm{moll}^{-1}$ and complete $\gamma$-reduction, of the absorbances at $220(\boldsymbol{\nabla}), 310(\triangle)$, and $400 \mathrm{~nm}(\boldsymbol{\nabla})$ of a mixed solution $\mathrm{Ag} / \mathrm{Rh}^{\mathrm{II}}$. Optical path $0.2 \mathrm{~cm}$.

at 310 and $400 \mathrm{~nm}$, because the intensity is minimized at about $\mathrm{Ag} / \mathrm{Rh}=1 / 3$ (Fig. 5b). This reproducible minimum is assigned to two opposite effects. At the increasing $\mathrm{Ag} /(\mathrm{Rh}+\mathrm{Ag})$ ratio, the $\mathrm{Rh}$ amount and its absorbance component in the total spectrum decrease while silver clusters contribute to the spectra less than their proportion: some rhodium clusters are sufficiently close to the silver surface such that they behave as a shell around the silver core and display a dominant influence on the surface plasmon spectrum of the floc. When the $\mathrm{Ag} /(\mathrm{Rh}+\mathrm{Ag})$ ratio still increases, the spectrum results from the contributions of $\mathrm{Rh}_{n}$ and $\mathrm{Ag}_{n}$ and the $\mathrm{Ag}_{n}$ component become more predominant according to the ratio, so that the intensity increases at $400 \mathrm{~nm}$ and decreases at $310 \mathrm{~nm}$.

\section{Conclusion}

In conclusion, rhodium and silver represent quite a unique couple among mixed systems studied by radiolysis so far. They do not form mixed clusters, in either a core-shell or an alloyed structure, even at a high dose rate. This is related to the mismatch in lattice parameters of the crystals which are quite different. In contrast, pure clusters of distinct sizes (larger for $\mathrm{Ag}_{n}$ than for $\mathrm{Rh}_{n}$ ) are formed. Beyond complete reduction, some cross-linking of polymer chains is favored and the clusters tend to be concentrated in flocs with $\mathrm{Ag}_{n}$ clusters surrounded by the small $\mathrm{Rh}_{n}$ clusters. The resulting optical absorption spectrum is qualitatively close to that of a plasmon band of silver clusters coated by an $\mathrm{Rh}$ shell as in bilayered clusters. 


\section{References}

Belloni, J., 1996. Metal nocolloids. Curr. Opin. Colloid Interface Sci. 1, 184-196.

Belloni, J., Mostafavi, M., Remita, H., Marignier, J.L., Delcourt, M.O., 1998. Radiation-induced synthesis of mono- and multi-metallic clusters and nanocolloids. New J. Chem. 22, 1239-1255.

Braunstein, P., Oro, L.A., Raithy, P.R. (Eds.), 1999. Metal Clusters in Chemistry. Wiley, Chichester, UK, VCH, Weinheim.

Buxton, G.V., Greenstock, C.L., Helman, W.P., Ross, A.B., 1988. J. Phys. Chem. Ref. Data 17, 513-886.

Chibber, R., Stradford, I.J., O'Neill, P., Sheldon, P.W., Ahmed, I., Lee, B., 1985. The interaction between radiation and complexes of cis-Pt(II) and $\mathrm{Rh}(\mathrm{I})$ : studies at the molecular and cellular level. Int. J. Radiat. Biol. 48, 513-524.

de Cointet, C., Khatouri, J., Mostafavi, M., Belloni, J., 1997. Coalescence and reactivity of gold-silver bimetallic clusters in cyanide solution. J. Phys. Chem. 101, 3517-3522.

Derai, R., Remita, H., Delcourt, M.O., 1991. Pulse radiolysis of $\left(\mathrm{Rh}^{\mathrm{I}}(\mathrm{CO})_{2} \mathrm{Cl}\right)_{2}$ and $\left(\mathrm{Rh}^{\mathrm{II}}\left(\mathrm{CH}_{3} \mathrm{COO}\right)_{2}\right)_{2}$ solutions under $\mathrm{CO}$ or N atmosphere. Radiat. Phys. Chem. 38, 483-486.

Gachard, E., Remita, H., Khatouri, J., Keita, B., Nadjo, L., Belloni, J., 1998. Radiation-induced an chemical formation of gold clusters. New J. Chem. 22, 1257-1265.

Hansen, M., Shunk, F.A., 1958. Constitution of binary alloys (metallurgy and metallurgical engineering series), 2nd Edition. Mc Graw-Hill, New York.

Harada, M., Asakura, K., Toshima, N., 1994. Structural analysis of polymer-protected platinum/rhodium bimetallic clusters using extended X-ray absorption fine structure spectroscopy. Importance of microclusters for the formation of bimetallic clusters. J. Phys. Chem. 98, 2653.

Henglein, A., 1993. Physicochemical properties of small metal particles in solution: microelectrode reactions, chemisorption, composite metal particles, and the atom-to-metal transition. J. Phys. Chem. 97, 5457-5471.

Henglein, A., Tausch-Treml, R., 1981. Optical absorption and catalytic activity of subcolloidal and colloidal silver in aqueous solution : a pulse radiolysis study. J. Colloid Interface Sci. 80, 84-93.

Keghouche, N., 1983. Agrégats métalliques préparés par voie radiolytique : préparation optimisée et tests catalytiques en vue d'application au stockage de l'énergie solaire. Thesis, Université Paris XI, Orsay.

Marignier, J.L., Belloni, J., Delcourt, M.O., Chevalier, J.P., 1985. New microaggregates of non-noble metals and alloys prepared by radiation induced reduction. Nature 317, 344-345.

Michaelis, M., Henglein, A., 1992. Reduction of Pd(II) aqueous solution : stabilization and reaction of an intermediate cluster and Pd colloid formation. J. Phys. Chem. 96, 4719.

Michaelis, M., Henglein, A., Mulvaney, P., 1994. Composite $\mathrm{Pd}-\mathrm{Ag}$ particles in aqueous solution. J. Phys. Chem. 98, 6212-6215.

Mills, G., Henglein, A., 1985. Radiation chemical formation of colloidal iridium and mechanism of catalysed hydrogen formation by radicals. Radiat. Phys. Chem. 26, 385-390.

Mulvaney, P., 1996. Surface plasmon spectroscopy of nanosized metal particles. Langmuir 12, 788-800.

Remita, H., Khatouri, J., Treguer, M., Amblard, J., Belloni, J., 1997. Silver-palladium clusters synthesized by radiolysis. Z. Phys. D 40, 127-130.

Remita, S., Picq, G., Mostafavi, M., 1999. Radiolytic formation of bilayered $\mathrm{Pt}_{\text {core }} / \mathrm{Au}_{\text {shell }}$ and $\mathrm{Pt}_{\text {shelll }} / \mathrm{Au}_{\text {core }}$ clusters in aqueous solution. Radiat. Phys. Chem. 54, 463-473.

Schmid, G. (Ed.), 1994. Clusters and Colloids from Theory to Applications. VCH, Weinheim.

Tong, Y.Y., Yonezawa, T., Toshima, N., van der Klink, J., 1996. Pt NMR of polymer-Pt/Pd bimetallic catalysts. J. Phys. Chem. 100, 730-733.

Torigoe, K., Nakajima, Y., Esumi, K., 1993. Preparation and characterization of colloidal silver-platinum alloys. J. Phys. Chem. 97, 8304-8309.

Tréguer, M., De Cointet, C., Remita, H., Khatouri, J., Mostafavi, M., Amblard, J., Belloni, J., 1998. Dose-rate effect on radiolytic synthesis of gold-silver bimetallic clusters in solution. J. Phys. Chem 102, 4310-4321.

Ulanski, P., Bothe, E., Rosiak, J.M., von Sonntag, C., 1994. $\mathrm{OH}$-radical-induced crosslinking and strand breakage of poly(vinyl alcohol) in aqueous solution in the absence and of oxygen. A pulse radiolysiproduct study. Macromol. Chem. Phys. 195, 1443-1447.

Ulanski, P., Janik, I., Rosiak, J.M., 1998. Radiation formation of polymeric nanogels. Radiat. Phys. Chem. 52, 289-294.

Von Pukies, J., Roebke, W., Henglein, A., 1968. Pulsradiolytische untersuchung einiger elementarprozesse der silberreduction. Ber. Bunsenges. Phys. Chem. 72, 842.

Wang, B., Mukataka, S., Kodama, M., Kokufuta, E., 1997. Viscometric and light scattering studies on microgel formation by $\gamma$-ray irradiation to aqueous oxygen-free solutions of poly(vinyl alcohol). Langmuir 13, 6108-6114. 